Check for updates

Cite this: Chem. Sci., 2019, 10, 4609

๑ All publication charges for this article have been paid for by the Royal Society of Chemistry

Received 24th January 2019

Accepted 19th March 2019

DOI: $10.1039 / c 9 s c 00412 b$

rsc.li/chemical-science

\title{
Reversible perovskite electrocatalysts for oxygen reduction/oxygen evolution $\uparrow$
}

\author{
Kieren Bradley, ${ }^{a}$ Kyriakos Giagloglou, ${ }^{a}$ Brian E. Hayden, (D)*ab Hugo Jungius ${ }^{a}$ \\ and Chris Vian ${ }^{a}$
}

The identification of electrocatalysts mediating both the oxygen reduction reaction (ORR) and oxygen evolution reaction (OER) are prerequisite for the development of reversible fuel cells and rechargeable metal-air batteries. The question remains as to whether a bifunctional catalyst, or a single catalyst site, will exhibit potentials converging to $+1.23 \mathrm{~V}_{\mathrm{RHE}}$. Transition metal-based perovskites provide tunable catalysts where site substitution can influence both ORR and OER, however substitution in the pseudobinary phases results in an anti-correlation in ORR and OER activities. We reveal that $\mathrm{La}_{x} \mathrm{Mn}_{y} \mathrm{Ni}_{1-y} \mathrm{O}_{3-\delta}$, compositions with lanthanum A-site sub-stoichiometry exhibit reversible activity correlating with the appearance of the $\mathrm{Mn}^{3+} / \mathrm{Mn}^{4+}$ redox couple. The $\mathrm{Mn}^{3+} / \mathrm{Mn}^{4+}$ couple is associated with $\mathrm{Mn}^{4+}$ co-existing with $\mathrm{Mn}^{3+}$ in the bulk, as $\mathrm{La}^{3+}$ is substituted by $\mathrm{Ni}^{2+}$ at the A-site to create a mixed valent system. We also show that a direct $\mathrm{A}$-site substitution by the $\mathrm{Ca}^{2+}$ cation in $\mathrm{La}_{x} \mathrm{Ca}_{1-x} \mathrm{Mn}_{y} \mathrm{O}_{3-\delta}$ perovskites also results in the creation of $\mathrm{Mn}^{4+}$, the appearance of the $\mathrm{Mn}^{3+} / \mathrm{Mn}^{4+}$ redox couple, and a concomitant reversible activity. These results highlight a general strategy of optimizing oxide electrocatalysts with reversible activity.

\section{Introduction}

Considerable effort has focused on the search for active and stable electrocatalysts for both the oxygen reduction reaction (ORR) in low temperature fuel cells (LTFC), and the oxygen evolution reaction (OER) which are more cost effective than those containing precious metals. As an additional challenge, there is an increasing interest in electrocatalysts for reversible low temperature fuel cells (RLTFC, also known as unitized regenerative fuel cells, URFC) because of their potential in distributed energy storage: a RLTFC will require catalysts with simultaneously low overpotentials for both ORR and OER. There is also a requirement for reversible ORR/OER electrocatalysts for efficient metal/air batteries. ${ }^{1}$ While the search for such "bi-functional catalysts" continues, the question also remains as to whether a single catalyst, or indeed a single site at such a catalyst, will produce potentials which converge towards the equilibrium potential of $+1.23 \mathrm{~V}_{\mathrm{RHE}}$ for ORR/OER.

Transition-metal oxides, and in particular perovskites, have been investigated as alternatives to the precious metal based catalysts as they can exhibit good OER or ORR activities. ${ }^{2}$ Studies of stoichiometric perovskites and A-site or B-site

\footnotetext{
allika Technologies, Kenneth Dibben House, Enterprise Road, Southampton Science Park, Southampton, SO167NS, UK.E-mail: beh@soton.ac.uk ${ }^{b}$ Chemistry, University of Southampton, Highfield, Southampton, SO17 1BJ, UK $\dagger$ Electronic supplementary information (ESI) available. See DOI: 10.1039/c9sc00412b
}

substituted perovskites are reported to exhibit a volcano activity dependence based on the common descriptor of the filling of the $\mathrm{e}_{\mathrm{g}}$-orbital of the transition metal B-site which determined the enthalpy of formation of adsorbed $\mathrm{OH}$ intermediate. ${ }^{3,4}$ The strategy of using the $\mathrm{e}_{\mathrm{g}}$-orbital descriptor to optimise A or B-site substituted perovskites for OER activity has been successful, ${ }^{4}$ although the approach did not necessarily predict an increase ORR activity for the same catalyst. ${ }^{5}$ The experimental investigations can be complicated, however, by the fact that there can be a synergic effect between perovskite and carbon supports, and the competition between $4 \mathrm{e}^{-}$reduction, and $2 \mathrm{e}^{-}$reduction to the peroxide intermediate. There appear to be a number of possible factors which are determining the effects of A-site and B-site substitution on OER and ORR activity, and it remains challenging to draw holistic conclusions to identify a unique strategy to optimise catalytic activity. ${ }^{2}$ The introduction of a small A-site deficiency (5\%) in $\mathrm{LaFeO}_{3}$ was reported to give a large increase in OER activity together with a slight improvement in ORR activity: ${ }^{6}$ this was ascribed to the creation of surface oxygen vacancies, highlighting a potential strategy for enhancing ORR and OER activity.

In the case of manganese oxides, the oxidation state of the bulk appears to strongly influence the ORR activity of the surface, with nano-structured alpha- $\mathrm{Mn}_{2} \mathrm{O}_{3}$ exhibiting high ORR and OER activity. ${ }^{7}$ This bi-functional activity has been rationalized through the application of density functional calculations which also suggest that the active surface for ORR 
is $1 / 2 \mathrm{ML} \mathrm{HO}^{*}$ on $\mathrm{Mn}^{3+}$ and for OER is $\mathrm{O}^{*}$ covered $\mathrm{Mn}^{4+}$. Amongst various manganese oxides, carbon supported $\mathrm{Mn}_{2} \mathrm{O}_{3}$ exhibited the highest activity for the ORR reaction, and a direct correlation activity and the potential of the $\mathrm{Mn}^{4+} / \mathrm{Mn}^{3+}$ redox couple. ${ }^{9}$ The proximity of the $\mathrm{Mn}^{4+} / \mathrm{Mn}^{3+}$ redox couple to the ORR/OER equilibrium potential appears to be an important factor in determining the activity of $\mathrm{Mn}$ oxide based catalysts. ${ }^{8}$

In Mn based perovskites, the oxidation state of $\mathrm{Mn}$ at the Bsite can be altered by substitution of cations at the A-site, partial substitution of manganese for a transition-metal in a B-site, or by altering the stoichiometry of oxygen. For example, $\mathrm{Sr}^{2+}$ and $\mathrm{Ca}^{2+}$ have been substituted for $\mathrm{La}^{3+}$ at the A-site, converting a proportion of the $\mathrm{Mn}^{3+}$ to $\mathrm{Mn}^{4+}$ on the B-site, resulting in an increase in the ORR activity. ${ }^{\mathbf{1 0 - 1 2}}$ In the case of $\mathrm{La}_{1-x} \mathrm{Sr}_{x} \mathrm{MnO}_{3}$, it was found that either $\mathrm{La}_{0.4} \mathrm{Sr}_{0.6} \mathrm{MnO}_{3}$ (nominal valence $\mathrm{Mn}^{3.6+}$ ) or $\mathrm{La}_{0.77} \mathrm{Sr}_{0.33} \mathrm{MnO}_{3}$ exhibit higher ORR activity compared to the other Sr doped perovskites. ${ }^{\mathbf{1 0 , 1 2}}$ It has also been found that if the perovskite is predominantly $\mathrm{Mn}^{4+}$ this results in reduced ORR activity., ${ }^{3,13}$ In applications to the $\mathrm{Zn}$-air cell, increasing $\mathrm{Ca}$ concentrations in graphite supported $\mathrm{La}_{1-x} \mathrm{Ca}_{x} \mathrm{MnO}_{3}$ resulted in an increase in the ORR activity, with $\mathrm{La}_{0.6} \mathrm{Ca}_{0.4} \mathrm{MnO}_{3}$ appearing to be the most active catalyst. ${ }^{\mathbf{1 4}}$ The ORR activity of $\mathrm{La}_{0.6} \mathrm{Ca}_{0.4} \mathrm{MnO}_{3}$ appeared improved in a number of A-site substoichiometric compositions. ${ }^{15}$ However, it has also been found that increasing the electron density at the Mn site in $\mathrm{LaCaMnO}_{3}$ results in an increase in ORR activity, with $\mathrm{LaMnO}_{3}$ exhibiting the lowest overpotential for the reaction. ${ }^{\mathbf{1 6}}$

To understand better the role of A and B-site substitution, and the role of A-site and B-site sub-stoichiometry, in Mn based perovskites, we have investigated both the ORR and OER activities of the $\mathrm{La}_{x} \mathrm{Mn}_{y} \mathrm{Ni}_{1-y} \mathrm{O}_{3-\delta}$ and $\mathrm{La}_{x} \mathrm{Ca}_{1-x} \mathrm{Mn}_{y} \mathrm{O}_{3-\delta}$ perovskites. The intrinsic activity of continuous thin film catalysts has been measured to exclude any effects of a carbon-based support, which may influence the reaction in the alkali environment. We have applied a combinatorial methodology employing metal evaporative sources combined with an oxygen plasma atom source has been shown ${ }^{\mathbf{1 7}}$ to produce stoichiometric $\mathrm{SrTi}_{1-x} \mathrm{Fe}_{x} \mathrm{O}_{3-y}$ perovskites which can be screened on chip for ORR and OER activity. The $\mathrm{LaMnNiO}_{3}$ (B-site substituted) system has been studied extensively for other purposes including the magnetic properties of the materials. ${ }^{18-20}$ Demina et $a .^{21}$ synthesised a number of compositions across the entire ternary composition space and developed a structural phase diagram. ORR catalytic activity is reported in the alkali environment for the $\mathrm{LaNi}_{0.5} \mathrm{Mn}_{0.5} \mathrm{O}_{3-\delta}$ perovskite: $\mathrm{LaNi}_{0.5} \mathrm{Mn}_{0.5} \mathrm{O}_{3-\delta}$ exhibits the largest current density and lowest overpotential in the series of $\mathrm{LaNi}_{0.5} \mathrm{M}_{0.5} \mathrm{O}_{3-\delta}$ perovskites $(\mathrm{M}=$ $\mathrm{Ni}, \mathrm{Co}, \mathrm{Fe}, \mathrm{Mn}$, and $\mathrm{Cr}) .{ }^{3,22,23}$ A-site substituted $\mathrm{La}_{1-x} \mathrm{Ca}_{x} \mathrm{MnO}_{3}$ perovskites have also been studied for their ORR electrocatalytic activity in alkaline media (above).

\section{Experimental}

Compositional gradient thin film libraries were deposited using a High Throughput Physical Vapour Deposition (HT-PVD) system described in more detail elsewhere. ${ }^{24}$ This system has previously been used to synthesise a number of different metal oxide perovskites which have subsequently been screened for their ferroelectric ${ }^{25}$ paraelectric, ${ }^{25-27}$ dielectric, ${ }^{28}$ ion conductive $^{29}$ and electrocatalytic ${ }^{17}$ properties. The constituent elements were deposited simultaneously using multiple off-axis Knudsen cell (k-cell) or electron beam (e-beam) sources, each source independently shadowed by a partial "wedge" shutter which controls the flux distribution across the substrate. The position of the wedge shutters controls the compositional region being deposited on the substrate. Lanthanum (Absco 99.95\%) was deposited from either a high temperature k-cell or an e-beam, nickel (Testborne 99.99\%) was deposited from an e-beam, calcium (Alfa Aesar 99.5\%) and manganese (Alfa Aesar 99.95\%) were deposited from a k-cell. Oxygen atoms were codeposited at the substrate by means of a plasma atom source (Oxford Applied Research or Mantis). Simultaneous mixing of the elements provides a low kinetic energy pathway to solid state oxide formation enabling a low temperature route to amorphous and crystalline stoichiometric oxides. Shadow masks were used to define confine oxide growth to discrete fields on the electrochemical chip.

The thin film libraries were deposited onto $35 \times 35 \mathrm{~mm} \mathrm{Si}$ / SiO substrates $(\langle 100\rangle$ silicon with $100 \mathrm{~nm}$ thermal silicon oxide) for composition and X-ray diffraction measurements. For electrochemical measurements, depositions were made on an electrochemical screening chip based on the design described elsewhere, ${ }^{30}$ but with indium tin oxide (ITO) tracks and pads. The ITO conductive layer was chosen for stability and electrochemical inactivity, and the connecting tracks were passivated by a layer of silicon oxide. All depositions were made with the substrate at $550{ }^{\circ} \mathrm{C}$ which was sufficient to produce the crystalline perovskite phases.

Elemental composition was measured by Energy-Dispersive X-ray Spectroscopy (EDX) (Tescan Vega 3 LMU SEM incorporating an Oxford Instruments X-Max 50, $50 \mathrm{~mm}^{2}$ large area SDD detector). The composition and thickness of the films were derived using LayerProbe software from Oxford Instruments. Crystal structures were determined by X-ray diffraction (XRD) (Bruker D8 diffractometer with GADDS detector and an Incoatec $\mathrm{Cu} \mathrm{K} \mathrm{K}_{\alpha}$ spot X-ray source). Compositions are reported in atomic percent (at\%) with an experimental error of \pm 2.5 at $\%$.

Electrochemical measurements were carried out using a glass cell, instrumentation and software specifically developed for high-throughput electrochemical screening. ${ }^{31}$ Combining the use of a single channel potentiostat and a multi-channel current follower, fast sequential monitoring of the electrode currents is achieved. The electrochemical measurements were performed in a three-compartment glass cell, especially designed to accommodate the high throughput array. A reference electrode ( $\mathrm{Hg} / \mathrm{HgO}$, Sentek) was mounted in a Luggin capillary with a tip situated a few millimetres away from the electrochemical array. Prior to each set of experiments the potential of the $\mathrm{Hg} / \mathrm{HgO}$ reference electrode was compared to a Gaskatel HydroFlex reference hydrogen electrode after 10 minutes equilibration in the experimental electrolyte. The counter electrode (a platinum mesh of area $\sim 4 \mathrm{~cm}^{2}$ and pitch $0.5 \mathrm{~mm}$ ) was separated from the array under test by a glass sinter. All experiments were conducted in $300 \mathrm{~mL}$ of $0.1 \mathrm{M} \mathrm{KOH}$ 
(>99\%, Sigma-Aldrich) solution the solution was either used saturated by oxygen or deoxygenated using argon bubbled through the cell. The ignition potentials which are extracted from the cyclic voltammetry measurement of ORR have been extracted at sufficiently low currents in this high throughput configuration $^{32}$ to avoid influenced from transport limitation of reactants. As part of the study, the resistance of the thin films was measured using a four-point probe. The resistivity of the films (ESI $\dagger$ ) was found to be sufficiently low to have a negligible effect on the electrochemical measurements. The catalysts were also subjected to an extended cycling routine of 200 cycles covering the potentials of both the OER and ORR regions in order to ensure that they were stable under the measurement conditions. There was no significant change in the voltammetry after the extended cycling.

\section{Results and discussion}

Synthesised thin film catalysts of $\mathrm{La}_{x} \mathrm{Mn}_{y} \mathrm{Ni}_{1-y} \mathrm{O}_{3-\delta}$ which were screened for their electrocatalytic activity (Fig. 1-3) were fully characterised structurally by X-ray diffraction (ESI $\dagger$ ). The perovskite is synthesised exclusively at all compositions in the region of the pseudo-binary line, and characterised by the four Bragg peaks (100), (110), (111) and (200). Bragg peaks associated with $\mathrm{NiO}$ and $\mathrm{MnO}_{2}$ phases are only observed at compositions with less than 30 at\% La, well away from the pseudo-binary line. It is evident that the $\mathrm{La}_{x} \mathrm{Mn}_{y} \mathrm{Ni}_{1-y} \mathrm{O}_{3-\delta}$ perovskites can accommodate a wide range of $\mathrm{Mn} / \mathrm{La}$ sub-stoichiometry. Along the pseudo-binary composition line there is a linear dependence of the (110) $2 \theta$ position which correspond to a gradual change from the cubic $\mathrm{LaMnO}_{3}(P m \overline{3} m)$ to the rhombohedral $\mathrm{LaNiO}_{3}$ $(R \overline{3} c)$ lattice. For compositions below $c a .10 \% \mathrm{Ni}$, however, there is a large scatter in the data towards higher $2 \theta$ values. There is also a range of $2 \theta$ values obtained for the cubic $\mathrm{LaMnO}_{3}(\mathrm{Pm} \overline{3} \mathrm{~m})$ which corresponds to a smaller lattice dimension that would be expected..$^{33}$ We suggest that this is a result of $\mathrm{La}^{3+}$ substitution by $\mathrm{Mn}^{2+}$ at the A-site. It is interesting to note that in the ternary compositions, there is also a region of La sub-stoichiometric compositions in the $\mathrm{Ni}$ poor composition region (up to $y=$ 0.2 in $\mathrm{La}_{x} \mathrm{Mn}_{y} \mathrm{Ni}_{1-y} \mathrm{O}_{3-\delta}$ ) where the (110) $2 \theta$ angle remains constant near to the value for $\mathrm{LaMnO}_{3}$. A likely explanation for this is that either $\mathrm{Ni}^{2+}$ or $\mathrm{Mn}^{2+}$ ions are also being co-ordinated in the La A-site, leading to a compensation in the lattice size as the B-site is accommodating $\mathrm{Ni}^{3+}$. Moreover, $\mathrm{Mn}^{2+}$ and $\mathrm{Ni}^{2+}$ exhibit same ionic radius $(70 \mathrm{pm})^{34}$ and could be either $\mathrm{Mn}^{2+}$ or $\mathrm{Ni}^{2+}$ on the A-site. $\mathrm{Mn}^{2+}$ has been substituted on the A-site in the $\mathrm{LaMnO}_{3},{ }^{35,36}$ in the $\mathrm{Ca}_{1-x} \mathrm{Mn}_{x} \mathrm{TiO}_{3}{ }^{37}$ and in the $\mathrm{Sr}_{1-x} \mathrm{Mn}_{x} \mathrm{TiO}_{3}$ system. ${ }^{38}$

We will show that it is this compositional region in which both the $\mathrm{Mn}^{3+} / \mathrm{Mn}^{4+}$ redox is evident and the perovskites exhibit the most reversible ORR/OER activity. In the absence of dissolved oxygen, cyclic voltammetry $(0.1 \mathrm{M} \mathrm{KOH}$ electrolyte, $5 \mathrm{mV}$ $\mathrm{s}^{-1}$ scan rate and room temperature) was used to identify the main redox couples associated with the $\mathrm{La}_{x} \mathrm{Mn}_{y} \mathrm{Ni}_{1-y} \mathrm{O}_{3-\delta}$ perovskites. Some examples of these are shown in ESI $\dagger$ obtained at several compositions. Three of the redox couples can be ascribed to the $\mathrm{Ni}^{2+} / \mathrm{Ni}^{3+}$ couple, ${ }^{39} \mathrm{Ni}^{0} / \mathrm{Ni}^{2+}$ couple ${ }^{40}$ and the $\mathrm{Mn}^{3+} / \mathrm{Mn}^{4+}$ couple ${ }^{8}$ centred at $1.45 \mathrm{~V}_{\mathrm{RHE}}, 0.4 \mathrm{~V}_{\mathrm{RHE}}$ and $1.0 \mathrm{~V}_{\mathrm{RHE}}$ respectively. The two pairs of Ni redox peaks were observed to have the largest integrated charge at high nickel concentrations in $\mathrm{La}_{x} \mathrm{Mn}_{y} \mathrm{Ni}_{1-y} \mathrm{O}_{3-\delta}$, and in the $\mathrm{LaNiO}_{3}$ binary. The compositional dependence of the charge associated with the $\mathrm{Ni}^{2+} / \mathrm{Ni}^{3+}$ couple centred at $1.45 \mathrm{~V}_{\mathrm{RHE}}$ (manifested as sharp anodic and cathodic peaks separated by $100 \mathrm{mV}$ ) was assessed by integrating the cathodic peak over the potential range $1.2<\mathrm{V}_{\mathrm{RHE}}<$ 1.45 and is shown in Fig. 1A. The charge for this couple increases with nickel content along the pseudo-binary composition line with the greatest charge identified in the $\mathrm{LaNiO}_{3}$ binary. There is also a region of $\mathrm{Ni}^{2+} / \mathrm{Ni}^{3+}$ redox activity, albeit with a much lower charge, in perovskites with lower $\mathrm{Ni}$ compositions, at La A-site sub-stoichiometric compositions. This corresponds to the same regions of composition which
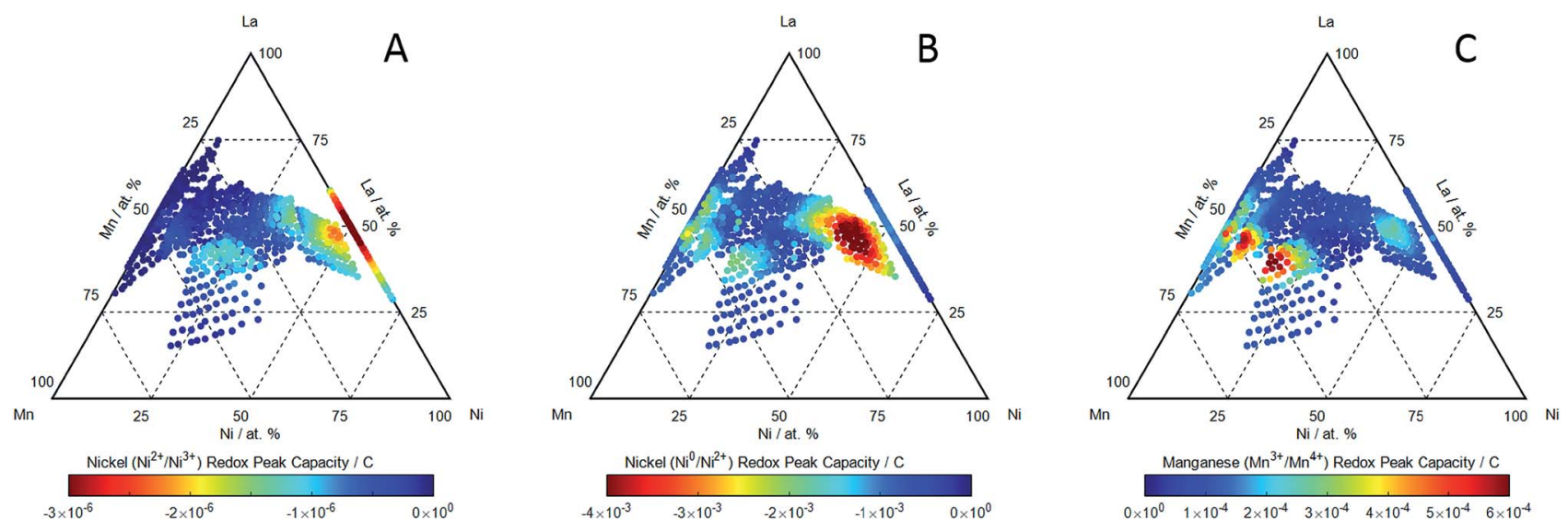

Fig. 1 The compositional dependence on $\mathrm{La}_{x} \mathrm{Mn}_{y} \mathrm{Ni}_{1-y} \mathrm{O}_{3-\delta}$ electrocatalysts of the charge associated with $(\mathrm{A})$ the $\mathrm{Ni}^{2+} / \mathrm{Ni}^{3+}$ couple (integrating the cathodic peak over the potential range $1.2<\mathrm{V}_{\mathrm{RHE}}<1.45$ ). (B) The $\mathrm{Ni}^{\mathrm{O}} / \mathrm{Ni}^{2+}$ couple (integrating the cathodic peak over the potential range $0.0<$ $V_{\mathrm{RHE}}<0.6$ ). (C) The $\mathrm{Mn}^{3+} / \mathrm{Mn}^{4+}$ couple (integrating the anodic peak over the potential range $0.9<\mathrm{V}_{\mathrm{RHE}}<1.15$ ). The data has been extracted from cyclic voltammetry $\left(0.1 \mathrm{M} \mathrm{KOH}\right.$ electrolyte, $5 \mathrm{mV} \mathrm{s}^{-1}$ scan rate, room temperature) recorded in deoxygenated $0.1 \mathrm{M} \mathrm{KOH}$, on a series of La ${ }^{-}$ $\mathrm{Mn}_{y} \mathrm{Ni}_{1-y} \mathrm{O}_{3-\delta}$ electrocatalyst thin film libraries. 

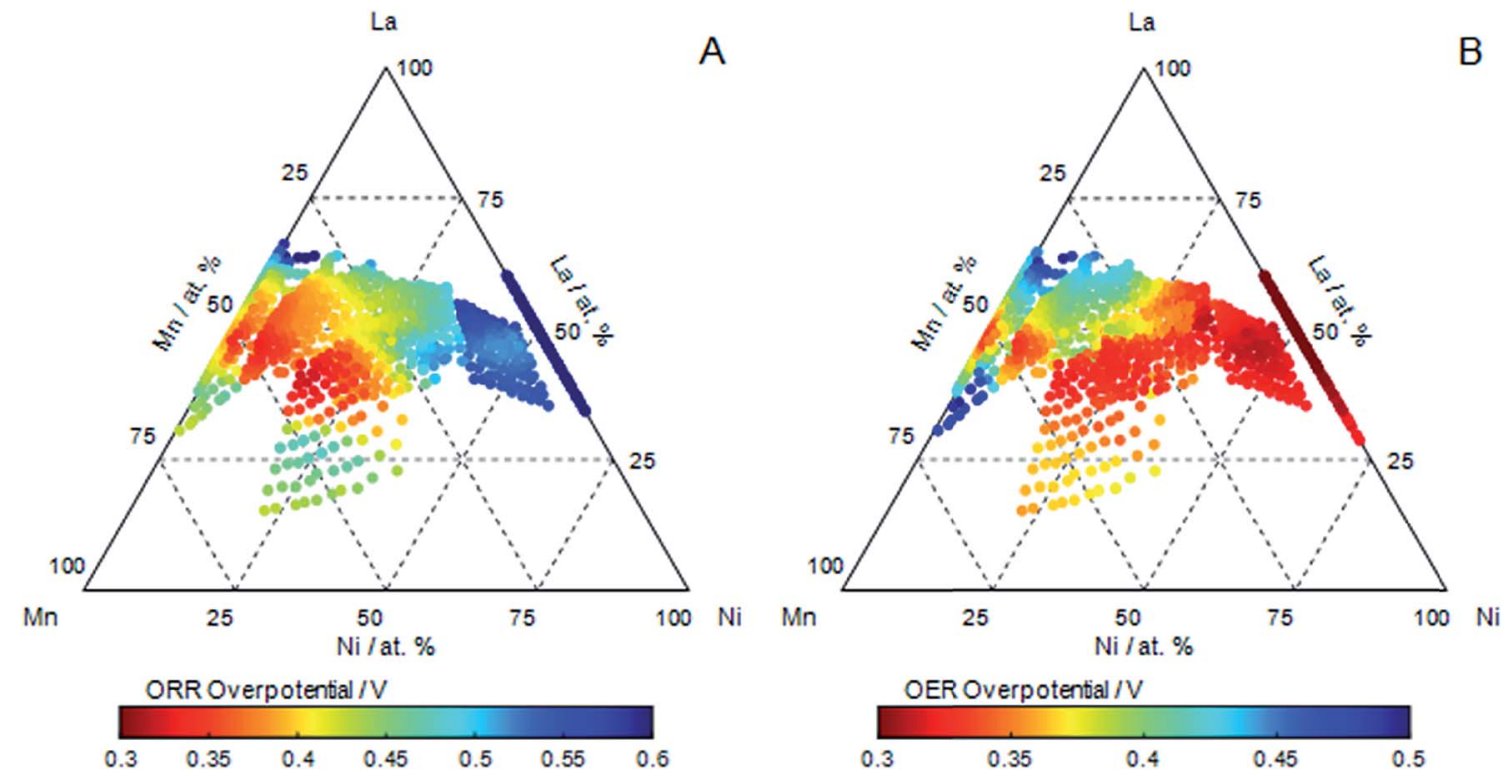

Fig. 2 The compositional dependence of the overpotential measured on $\mathrm{La}_{x} \mathrm{Mn}_{y} \mathrm{Ni}_{1-y} \mathrm{O}_{3-\delta}$ thin film electrocatalysts using cyclic voltammetry for: (A) the Oxygen Reduction Reaction (ORR) calculated from the ignition potential at $-20 \mu \mathrm{A} \mathrm{cm}{ }^{-2}$ in the cathodic scan and (B) the Oxygen Evolution Reaction OER calculated from the ignition potential at $40 \mu \mathrm{A} \mathrm{cm}^{-2}$. Measurements have been made at a scan speed of $5 \mathrm{mV} \mathrm{s}^{-1}$ in oxygen saturated $0.1 \mathrm{M} \mathrm{KOH}$ at $25^{\circ} \mathrm{C}$. The experimental error in the overpotentials is $\pm 10 \mathrm{mV}$.

exhibited a smaller than expected lattice parameter in the diffraction (ESI $\dagger$ ) which we associated with $\mathrm{Mn}^{2+}$ or $\mathrm{Ni}^{2+}$ at the Asite: the appearance of the $\mathrm{Ni}^{2+} / \mathrm{Ni}^{3+}$ redox in this composition region suggests that there is $\mathrm{Ni}^{2+}$ in the $\mathrm{A}$-site. The compositional dependence of the charge associated with the $\mathrm{Ni}^{0} / \mathrm{Ni}^{2+}$ couple centred at $0.4 \mathrm{~V}_{\mathrm{RHE}}$ (manifested as broad anodic and cathodic peaks separated by $c a .400 \mathrm{mV}$ ) was assessed by integrating the cathodic peak over the potential range $0.0<\mathrm{V}_{\mathrm{RHE}}<0.6$ and is shown in Fig. 1B. The highest integrated charge is observed along the pseudo-binary composition line, increasing with the $\mathrm{Ni}$ content of the perovskite, but is reduced again for $\mathrm{LaNiO}_{3}$.
The compositional dependence of the charge associated with the $\mathrm{Mn}^{3+} / \mathrm{Mn}^{4+}$ couple centred at $1.0 \mathrm{~V}_{\mathrm{RHE}}$ (manifested as broad anodic and cathodic peaks separated by $200 \mathrm{mV}$ ) was assessed by integrating the anodic peak over the potential range $0.9<$ $\mathrm{V}_{\mathrm{RHE}}<1.15$ and is shown in Fig. 1C. It is observed with the highest charge for perovskites with a lower Ni content, where $y>$ 0.25 in $\mathrm{La}_{x} \mathrm{Mn}_{y} \mathrm{Ni}_{1-y} \mathrm{O}_{3-\delta}$. The compositional region where it is observed, however, is exclusively for compositions with La A-site sub-stoichiometry (Fig. 1C): the maximum in the $\mathrm{Mn}^{3+} / \mathrm{Mn}^{4+}$ charge density for the anodic sweep is observed for $\mathrm{La}_{0.85^{-}}$ $\mathrm{Mn}_{0.7} \mathrm{Ni}_{0.45} \mathrm{O}_{3-\delta}$. The apparent substitution of $\mathrm{La}^{3+}$ at the A-site
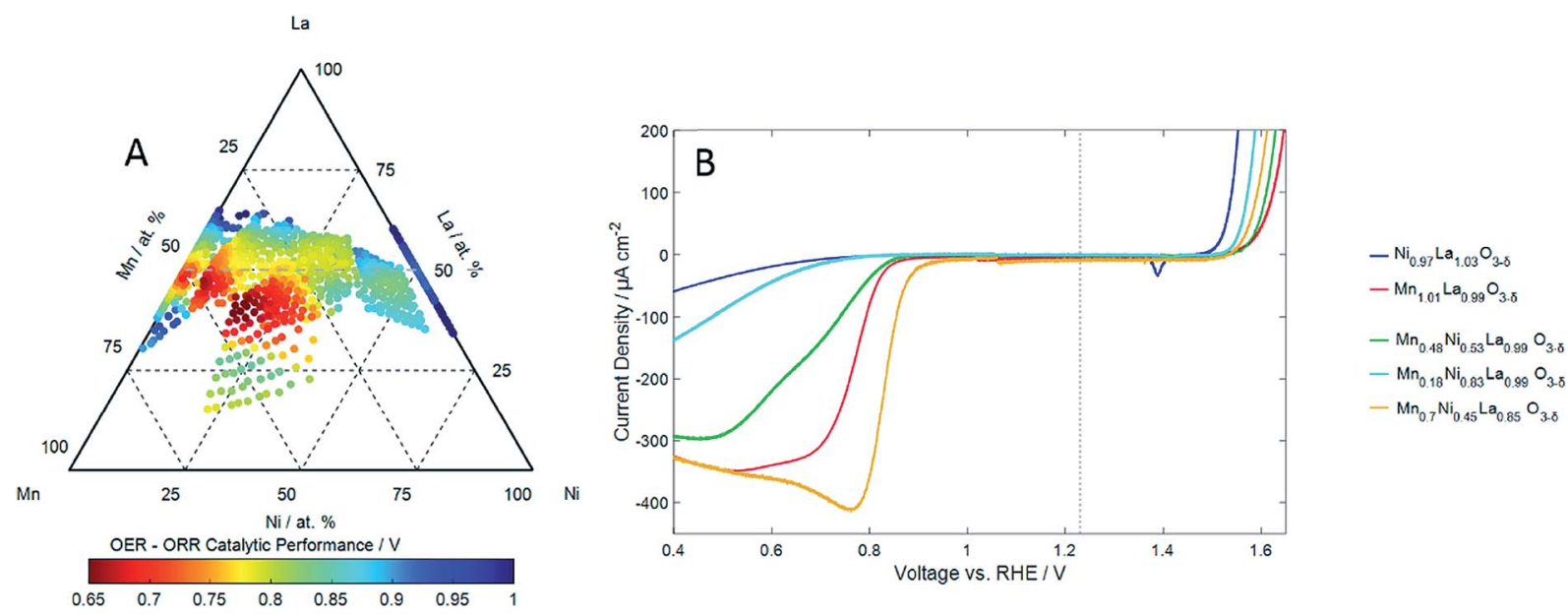

Fig. 3 (A) The compositional dependence of the reversibility of the ORR/OER on $\mathrm{La}_{x} \mathrm{Mn}_{y} \mathrm{Ni}_{1-y} \mathrm{O}_{3-\delta}$ thin film electrocatalysts expressed as the difference between the ORR and OER overpotentials (Fig. 2) with an experimental error of $\pm 15 \mathrm{mV}$. (B) Cyclic voltammograms of the ORR and OER showing the reactions at for selected compositions. Measurements have been made at a scan speed of $5 \mathrm{mV} \mathrm{s}$ in oxygen saturated $0.1 \mathrm{M}$ $\mathrm{KOH}$ at $25^{\circ} \mathrm{C}$. 
by what we believe is likely to be mainly $\mathrm{Ni}^{2+}$ is apparently directly correlated with the appearance of the $\mathrm{Mn}^{3+} / \mathrm{Mn}^{4+}$ redox couple. We suggest that it is the multivalent Mn cation environment created by a divalent ion substitution $\left(\mathrm{Ni}^{2+}\right.$ at the A-site creating a $\mathrm{Mn}^{4+}$ environment at the B-site).

The oxygen reduction reaction (ORR) and oxygen evolution reaction (OER) were measured on the catalyst libraries using cyclic voltammetry. Examples of ORR activities in cathodic sweeps of a series of catalysts with pseudo-binary compositions measured in oxygen saturated electrolyte are shown in ESI. $\dagger$ The ORR activity of $\mathrm{LaNiO}_{3}$ is seen to be very poor, and substitution with $\mathrm{Mn}$ increases activity, with the ignition potential $(-20 \mu \mathrm{A}$ $\mathrm{cm}^{-2}$ ) moving to higher values, and the reduction currents increase more steeply. The best performing ORR catalyst are observed for $\mathrm{LaMn}_{0.45} \mathrm{Ni}_{0.05} \mathrm{O}_{3-\delta}$, and ORR activity drops at lower Ni content. The use of planar electrodes without hydrodynamic flow results in the current being mass transfer limited above a small overpotential. Consequently, ignition potential is used to define the capability of the materials as catalysts: ${ }^{17}$ additionally, to aid interpretation of the results, the ignition potentials are reported as an over potential with respect to the reversible oxygen potential of $1.23 \mathrm{~V}$ in Fig. $2 \mathrm{~A}$ over the compositions investigated. This clearly shows that the compositions of highest ORR activity are for $\mathrm{LaMnO}_{3}$ and increase further for a range of A-site La sub-stoichiometric compositions of $\mathrm{LaMn}_{0.45} \mathrm{Ni}_{0.05} \mathrm{O}_{3-\delta}$.

Examples of OER activities in anodic sweeps of a series of catalysts with pseudo-binary compositions are shown in ESI. $\dagger$ The OER activity is greatest for $\mathrm{Ni}$ rich compositions in $\mathrm{La}_{x}{ }^{-}$ $\mathrm{Mn}_{y} \mathrm{Ni}_{1-y} \mathrm{O}_{3-\delta}$, with the lowest activity for compositions at low nickel substitution, it should be noted that the addition of manganese generally has a negative effect on the OER activity. However, as in the case of the ORR reaction, the compositional dependence of the OER reaction is complex. The overpotential for the OER reaction based on the ignition potential $(40 \mu \mathrm{A}$ $\mathrm{cm}^{-2}$ ) is plotted as a function of composition for the catalysts investigated in Fig. 2B. The OER activity along the pseudobinary compositions of $\mathrm{La}_{x} \mathrm{Mn}_{y} \mathrm{Ni}_{1-y} \mathrm{O}_{3-\delta}$ decrease with decreasing $\mathrm{Ni}$ content, although increase again slightly for $\mathrm{LaMnO}_{3}$.

The compositional dependence of the ORR and OER activities along the pseudo-binary compositions $\mathrm{La}_{x} \mathrm{Mn}_{y} \mathrm{Ni}_{1-y} \mathrm{O}_{3-\delta}$ highlight that there is, in general, an anti-correlation in the activities of the catalysts: overpotentials for OER are lowest for $\mathrm{Ni}$ rich compositions, and overpotentials for ORR are lowest for Mn rich compositions. The overpotentials we observe for the ORR active $\mathrm{LaMnO}_{3}$ catalyst, and the OER active $\mathrm{LaNiO}_{3}$ are in good agreement to those reported elsewhere. ${ }^{3,4}$ It is also clear, by comparison with the main redox activities of $\mathrm{Ni}$ and $\mathrm{Mn}$, shown in Fig. 1, that there is no direct correlation of ORR or OER activity with the redox processes identified.

There is, however, a region of compositional space that evidently does not show this anti-correlation in the ORR and OER activities (Fig. 2). Catalysts which exhibit both ORR and OER activities are found for a region of A-site deficient compositions of $\mathrm{La}_{x} \mathrm{Mn}_{y} \mathrm{Ni}_{1-y} \mathrm{O}_{3-\delta}$. These are for compositions with Ni contents below 50 at\%. To identify compositions that exhibit both good OER and ORR activities, i.e. the catalysts exhibiting the most reversible OER/ORR behaviour, Fig. 3A shows the compositional dependence of the difference in the ORR and OER overpotentials for the catalysts investigated. The most reversible catalysts are clearly seen in the region which is expected to be A-site sub-stoichiometric of the perovskite. The most active reversible electrocatalyst corresponds to compositions around $\mathrm{La}_{0.85} \mathrm{Mn}_{0.7} \mathrm{Ni}_{0.45} \mathrm{O}_{3-\delta}$. Fig. 3B provide examples of the convergence of the ORR and OER overpotentials towards equilibrium. The strongest performing catalyst (orange) has the lowest ORR over potential, yet unlike the other voltammetry taken from the pseudo-binary tie-line, there is not a correlating poor OER over potential, resulting in a reversible catalyst. $\mathrm{La}_{0.85} \mathrm{Mn}_{0.7} \mathrm{Ni}_{0.45} \mathrm{O}_{3-\delta}$ exhibits an ORR overpotential even lower than $\mathrm{LaMnO}_{3}$, (considered an excellent ORR electrocatalyst) but now also an overpotential for OER similar to that found for one of the most active OER electrocatalysts $\mathrm{Ba}_{0.5} \mathrm{Sr}_{0.5} \mathrm{Co}_{0.8} \mathrm{Fe}_{0.2} \mathrm{O}_{3+\delta} .{ }^{3,4}$

Striking is the correlation between catalyst compositions which exhibit the most reversible OER/ORR activities (Fig. 3A), and those which exhibit the highest charge associated with the $\mathrm{Mn}^{3+} / \mathrm{Mn}^{4+}$ redox activities (Fig. 1C). There is evidently a role that the $\mathrm{Mn}^{3+} / \mathrm{Mn}^{4+}$ couple plays in catalysing both the ORR and OER reactions simultaneously. The reaction sites that support either the ORR or OER reaction along the pseudo-binary compositions of $\mathrm{La}_{x} \mathrm{Mn}_{y} \mathrm{Ni}_{1-y} \mathrm{O}_{3-\delta}$ (but not both reactions simultaneously) are evidently not the same site associated with the $\mathrm{Mn}^{3+} / \mathrm{Mn}^{4+}$ which is not observed for these stoichiometries (Fig. 1C).

The association of the $\mathrm{Mn}^{3+} / \mathrm{Mn}^{4+}$ redox couple with ORR activity is consistent with the observation that the oxidation state on manganese oxides which can result in this couple, and increase ORR activity. ${ }^{9}$ The uniqueness of the ability of the $\mathrm{Mn}^{3+} / \mathrm{Mn}^{4+}$ to also sustain reversible ORR/OER is also consistent with the arguments that it is $\mathrm{OH}$ adsorbed at the $\mathrm{Mn}^{3+}$ site which is active in ORR, and $\mathrm{O}$ adsorbed at $\mathrm{Mn}^{4+}$ for the OER activity. ${ }^{8}$ It will therefore be the proximity of the $\mathrm{Mn}^{3+} / \mathrm{Mn}^{4+}$ to the ORR/OER equilibrium potential together with the reversibility of the surface redox which will determine the ultimate reversibility of this reaction at such a bifunctional site.

The explanation for the appearance of the $\mathrm{Mn}^{3+} / \mathrm{Mn}^{4+}$ redox couple and the concomitant ORR/OER reversible activity at an A-site sub-stoichiometry compositions in $\mathrm{La}_{x} \mathrm{Mn}_{y} \mathrm{Ni}_{1-y} \mathrm{O}_{3-\delta}$ can be explained for this B-site substituted perovskite if one assumes that $\mathrm{Ni}^{3+}$ can not only be incorporated at the $\mathrm{B}$-site, but can be incorporated as $\mathrm{Ni}^{2+}$ at the A-site. ${ }^{41,42}$ This is equivalent to the classical divalent substitution of the La A-site which is known to achieve charge balance by inducing similar concentrations of $\mathrm{Mn}^{4+} \cdot{ }^{43}$ It is apparently the creation of $\mathrm{Mn}^{4+}$ in addition to $\mathrm{Mn}^{3+}$ in a mixed valance system that is important in introducing the $\mathrm{Mn}^{3+} / \mathrm{Mn}^{4+}$ redox couple. This model is also consistent with the observation that the optimum catalyst has a composition around $\mathrm{La}_{0.85} \mathrm{Mn}_{0.7} \mathrm{Ni}_{0.45} \mathrm{O}_{3-\delta}$ : the limit of lattice stability with A-site deficiency has been shown to be around an A-site sub-stoichiometry of about 10 at $\%{ }^{42,44,45}$

In order to test the thesis that A-site sub-stoichiometry of $\mathrm{Mn}$ based perovskites can lead to the appearance of the $\mathrm{Mn}^{3+} / \mathrm{Mn}^{4+}$ 


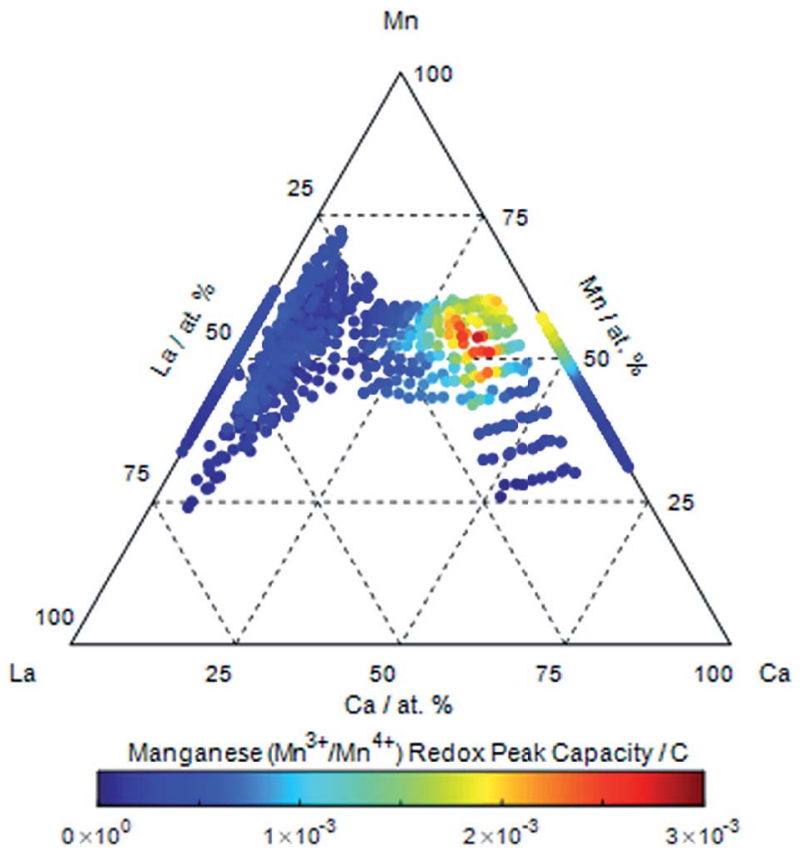

Fig. 4 The compositional dependence of the charge associated with $\mathrm{Mn}^{3+} / \mathrm{Mn}^{4+}$ redox couple (integrating the anodic peak over the potential range $\left.0.9<\mathrm{V}_{\mathrm{RHE}}<1.15\right)$ on $\mathrm{La}_{x} \mathrm{Ca}_{1-x} \mathrm{Mn}_{y} \mathrm{O}_{3-\delta}$ electrocatalysts. The data has been extracted from cyclic voltammetry $0.1 \mathrm{M} \mathrm{KOH}$ electrolyte, $5 \mathrm{mV} \mathrm{s}{ }^{-1}$ scan rate, room temperature) recorded in deoxygenated $0.1 \mathrm{M} \mathrm{KOH}$, on a series of $\mathrm{La}_{x} \mathrm{Ca}_{1-x} \mathrm{Mn}_{y} \mathrm{O}_{3-\delta}$ electrocatalyst thin film libraries.

redox couple, and a concomitant increase in the ORR/OER reversible activity, we have also investigated the $\mathrm{La}_{x} \mathrm{Ca}_{1-x} \mathrm{Mn}_{y^{-}}$ $\mathrm{O}_{3-\delta}$ perovskites. The inclusion of Ca should result in a direct substitution of the La A-site by the divalent cation. ${ }^{15,46,47}$ This type of substitution of the A-site by a divalent ion is well known for the formation of a mixture of $\mathrm{Mn}^{3+}$ and $\mathrm{Mn}^{4+}$ cations in the lattice. ${ }^{48-52} \mathrm{~A}$ series of the $\mathrm{La}_{x} \mathrm{Ca}_{1-x} \mathrm{Mn}_{y} \mathrm{O}_{3-\delta}$ perovskite libraries were synthesised and characterised for their electrochemical behaviour (Fig. 4-6), and characterised by X-ray diffraction (ESI†). The perovskite (Pnma) was identified over the region of compositions investigated around the pseudo-binary composition line, although the region where the $\mathrm{Ca}: \mathrm{La}$ ratio was greater than $c a .3: 1$ catalysts were poorly crystallised. Along the perovskite pseudo-binary composition line $\mathrm{La}_{x} \mathrm{Ca}_{1-x} \mathrm{Mn}_{y} \mathrm{O}_{3-\delta}$, a continuous A-site substitution in a cubic $(P m \overline{3} m)$ to orthorhombic (Pnma) perovskite solid solution is exhibited.

In the absence of dissolved oxygen, three manganese redox couples can be identified in the cyclic voltammetry (ESI + ). The $\mathrm{Mn}^{2+} / \mathrm{Mn}^{3+}, \mathrm{Mn}^{3+} / \mathrm{Mn}^{4+}$ and $\mathrm{Mn}^{2+} / \mathrm{Mn}^{4+}$ couples ${ }^{8}$ centred at 0.6 $\mathrm{V}_{\mathrm{RHE}}, 0.9<\mathrm{V}_{\mathrm{RHE}}<1.0$ and $1.1 \mathrm{~V}_{\mathrm{RHE}}$ respectively, are identified over the compositional range of $\mathrm{La}_{x} \mathrm{Ca}_{1-x} \mathrm{Mn}_{y} \mathrm{O}_{3-\delta}$ investigated. The $\mathrm{Mn}^{2+} / \mathrm{Mn}^{3+}$ couple is identified at potentials which shift with composition in the region 0.4 to $0.8 \mathrm{~V}_{\mathrm{RHE}}{ }^{53}$ and is present across the $\mathrm{La}_{x} \mathrm{Ca}_{1-x} \mathrm{Mn}_{y} \mathrm{O}_{3-\delta}$ perovskites compositional range. Substitution of $\mathrm{Ca}$ in the lattice results in a reduction in the charge associated with the $\mathrm{Mn}^{2+} / \mathrm{Mn}^{3+}$ couple. The $\mathrm{Mn}^{3+} / \mathrm{Mn}^{4+}$ couple observed at potentials $0.9-1.2 \mathrm{~V}_{\mathrm{RHE}},{ }^{8}$ is in the same potential range where the couple is observed in $\mathrm{La}_{x} \mathrm{Mn}_{y} \mathrm{Ni}_{1-y^{-}}$ $\mathrm{O}_{3-\delta}\left(\mathrm{ESI}^{\dagger}\right)$. With the increasing calcium content, the peak is seen to shift to higher potentials. But most importantly, the integrated charge density of this couple increases with $\mathrm{Ca}$ substitution in $\mathrm{La}_{x} \mathrm{Ca}_{1-x} \mathrm{Mn}_{y} \mathrm{O}_{3-\delta}$. The integrated charge of the cathodic peak of this couple is plotted as a function of composition in Fig. 4. Increasing the Ca content in $\mathrm{La}_{x} \mathrm{Ca}_{1-x^{-}}$ $\mathrm{Mn}_{y} \mathrm{O}_{3-\delta}$ along the pseudo-binary composition line results in an increase in the charge associated with the $\mathrm{Mn}^{3+} / \mathrm{Mn}^{4+}$ couple with a maximum at $\mathrm{La}_{0.3} \mathrm{Ca}_{0.7} \mathrm{MnO}_{3-\delta}$. A slightly higher
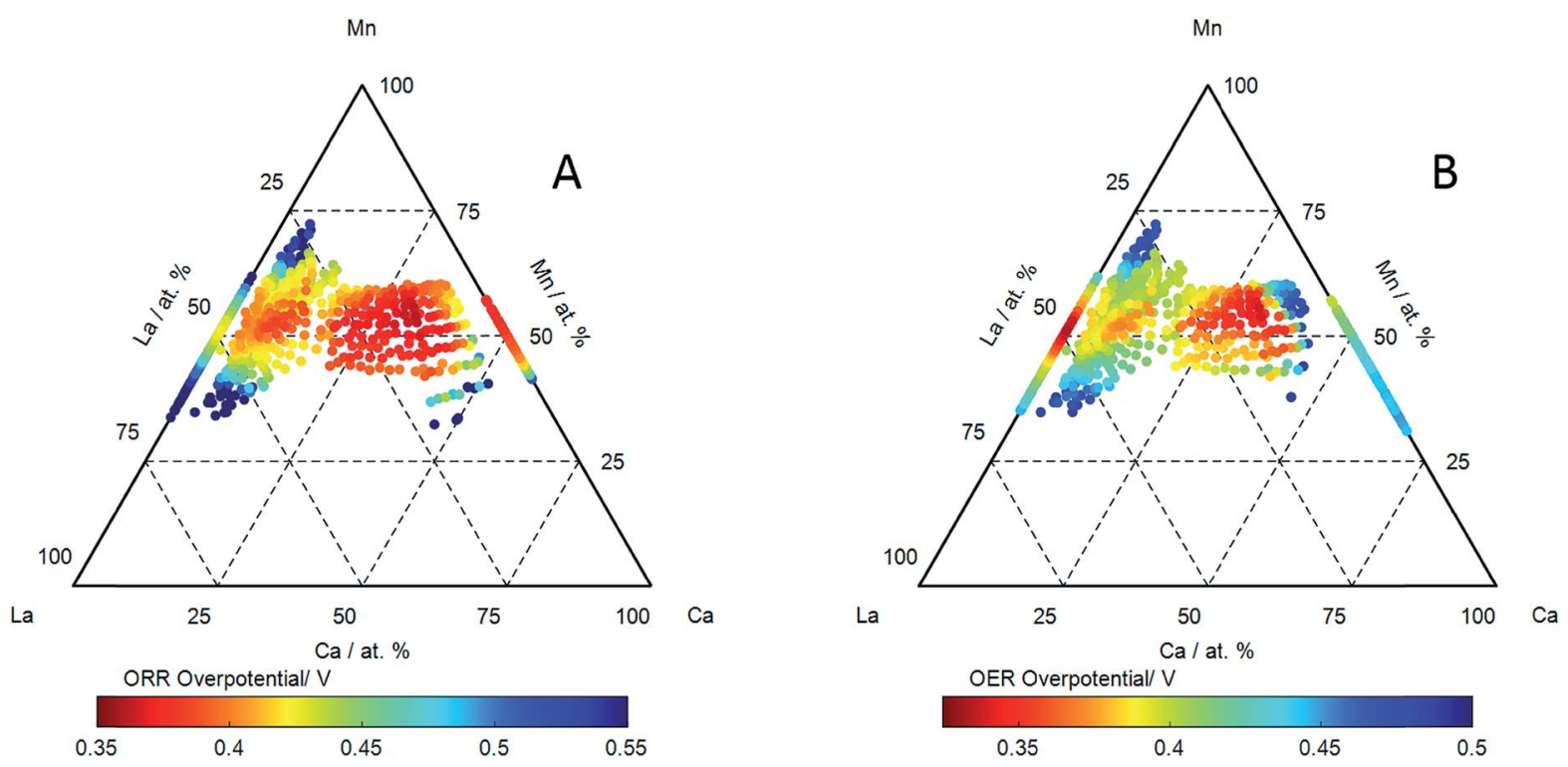

Fig. 5 The compositional dependence of the overpotential measured on $\mathrm{La}_{x} \mathrm{Ca}_{1-x} \mathrm{Mn}_{y} \mathrm{O}_{3-\delta}$ thin film electrocatalysts using cyclic voltammetry for: (A) the Oxygen Reduction Reaction (ORR) calculated from the ignition potential at $-70 \mu \mathrm{A} \mathrm{cm}^{-2}$ in the cathodic scan and (B) the Oxygen Evolution Reaction OER calculated from the ignition potential at $40 \mu \mathrm{A} \mathrm{cm}{ }^{-2}$. Measurements have been made at a scan speed of $5 \mathrm{mV} \mathrm{s}^{-1}$ in oxygen saturated $0.1 \mathrm{M} \mathrm{KOH}$ at $25^{\circ} \mathrm{C}$. The experimental error in the overpotentials is $\pm 10 \mathrm{mV}$. 

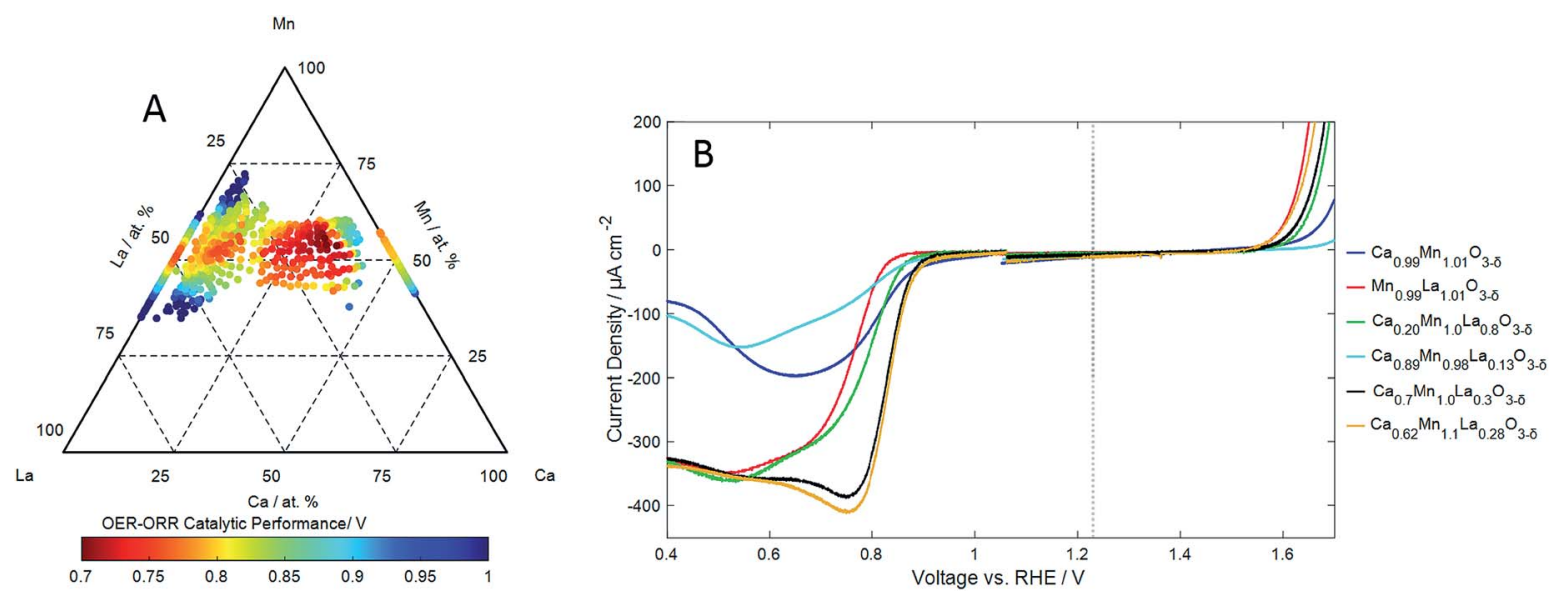

Fig. 6 (A) The compositional dependence of the reversibility of the ORR/OER on $\mathrm{La}_{x} \mathrm{Ca}_{1-x} \mathrm{Mn}_{y} \mathrm{O}_{3-\delta}$ thin film electrocatalysts expressed as the difference between the ORR and OER overpotentials (Fig. 5) with an experimental error of $\pm 15 \mathrm{mV}$. (B) Cyclic voltammograms of the ORR and OER showing the reactions at for selected compositions. Measurements have been made at a scan speed of $5 \mathrm{mV} \mathrm{s}{ }^{-1}$ in oxygen saturated $0.1 \mathrm{M}$ $\mathrm{KOH}$ at $25^{\circ} \mathrm{C}$.

maximum in the charge is observed for $\mathrm{La}_{0.3} \mathrm{Ca}_{0.6} \mathrm{Mn}_{1.1} \mathrm{O}_{3-\delta}$. At higher concentrations of $\mathrm{Ca}$, this couple decreases in charge, and the $\mathrm{Mn}^{2+} / \mathrm{Mn}^{4+}$ couple predominates in $\mathrm{CaMnO}_{3}$, a charge is still observed for the high Ca samples despite a lack of the $\mathrm{Mn}^{3+} / \mathrm{Mn}^{4+}$ couple; the $\mathrm{Mn}^{2+} / \mathrm{Mn}^{4+}$ peaks are large and broad, thus making complete dissociation difficult. This observation is consistent with the model in which the introduction of a divalent ion such as Ca in the A-site causes a charge deficiency in the structure resulting in the generation of $\mathrm{Mn}^{4+}$ at the B-site. ${ }^{43} \mathrm{As}$ was observed in the case of $\mathrm{La}_{x} \mathrm{Mn}_{y} \mathrm{Ni}_{1-y} \mathrm{O}_{3-\delta}$ (Fig. 3C), the generation of the $\mathrm{Mn}^{3+} / \mathrm{Mn}^{4+}$ couple is associated with the formation of $\mathrm{Mn}^{4+}$ in the lattice.

The oxygen reduction reaction (ORR) and oxygen evolution reaction (OER) were measured on the catalyst libraries using cyclic voltammetry. Examples of ORR activities (measured in cyclic voltammetry) in cathodic sweeps of a series of catalysts with pseudo-binary compositions measured in oxygen saturated electrolyte are shown in ESI. $\dagger$ An ignition potential for the ORR reaction has been extracted (at a current of $-70 \mu \mathrm{A} \mathrm{cm}{ }^{-2}$ ) and reported an effective overpotential with respect to the reversible oxygen potential of $1.23 \mathrm{~V}$, and this is shown as a function of composition of $\mathrm{La}_{x} \mathrm{Ca}_{1-x} \mathrm{Mn}_{y} \mathrm{O}_{3-\delta}$ in Fig. 5A. The ORR activity is seen to be good at all compositions along the pseudo-binary compositions of $\mathrm{La}_{x} \mathrm{Ca}_{1-x} \mathrm{Mn}_{y} \mathrm{O}_{3-\delta}$, however the addition of calcium to $\mathrm{LaMnO}_{3}$ (which shows the highest overpotential) results in a continuous reduction in the ORR overpotential. The lowest overpotential for the ORR reaction was observed for a calcium A-site substituted lattice composition of $\mathrm{La}_{0.3} \mathrm{Ca}_{0.6^{-}}$ $\mathrm{Mn}_{1.1} \mathrm{O}_{3-\delta}$ of $0.362 \mathrm{~V}$, along the pseudo-binary line, the highest overpotential was $0.368 \mathrm{~V}$ for $\mathrm{La}_{0.3} \mathrm{Ca}_{0.7} \mathrm{MnO}_{3-\delta}$.

Examples of OER activities (measured in cyclic voltammetry) in anodic sweeps of a series of catalysts with pseudo-binary compositions measured in oxygen free electrolyte are shown in ESI. $\dagger$ The effective overpotential for the OER reaction (extracted from the ignition potential at $40 \mu \mathrm{A} \mathrm{cm}^{-2}$ ) as a function of composition in $\mathrm{La}_{x} \mathrm{Ca}_{1-x} \mathrm{Mn}_{y} \mathrm{O}_{3-\delta}$ is shown in Fig. 5B.
The overpotential for OER is relatively low on $\mathrm{LaMnO}_{3} \cdot \mathrm{LaMnO}_{3}$ also exhibits the highest overpotential for ORR. The introduction of $\mathrm{Ca}$ in $\mathrm{LaMnO}_{3}$ initially results in an increase in the OER overpotential in $\mathrm{La}_{x} \mathrm{Ca}_{1-x} \mathrm{Mn}_{y} \mathrm{O}_{3-\delta}$ up to $c a .20 \% \mathrm{Ca}$. The ORR reaction exhibits a reduction in overpotential with increase in Ca concentration for these compositions. These compositions (for $\mathrm{Ca}<20 \%$ ) of $\mathrm{La}_{x} \mathrm{Ca}_{1-x} \mathrm{Mn}_{y} \mathrm{O}_{3-\delta}$ are therefore characterised by an anti-correlation of OER and ORR activities. However, a decrease in the overpotential for the OER is observed in $\mathrm{La}_{x^{-}}$ $\mathrm{Ca}_{1-x} \mathrm{Mn}_{y} \mathrm{O}_{3-\delta}$ for concentrations above $c a .20$ at $\%$ Ca: a continuing reduction in ORR overpotential is also observed. This results in a region of $\mathrm{La}_{x} \mathrm{Ca}_{1-x} \mathrm{Mn}_{y} \mathrm{O}_{3-\delta}$ compositions which exhibit a high activity for both OER and ORR reactions. This effect is again best exemplified in a plot of the difference between the OER and ORR potential as a function of composition: this reflects the effectiveness of the catalyst in the reversible reaction. This is shown in Fig. 6A, with some examples of the corresponding OER and ORR voltammograms shown in Fig. 6B. The region of highest reversible activity along the pseudo-binary composition line is centred at $\mathrm{La}_{0.3} \mathrm{Ca}_{0.7} \mathrm{MnO}_{3-\delta}$ with the most reversible activity observed for $\mathrm{La}_{0.3} \mathrm{Ca}_{0.6} \mathrm{Mn}_{1.1^{-}}$ $\mathrm{O}_{3-\delta}$. Comparison of Fig. 6A with Fig. 4 also reveals that the region of composition exhibiting the highest reversible activity also corresponds to the region of compositions exhibiting the most prominent $\mathrm{Mn}^{3+} / \mathrm{Mn}^{4+}$ redox activity.

\section{Conclusion}

A thin film combinatorial synthetic methodology has been used successfully to synthesise libraries of hundreds of thin film $\mathrm{La}_{x} \mathrm{Mn}_{y} \mathrm{Ni}_{1-y} \mathrm{O}_{3-\delta}$ and $\mathrm{La}_{x} \mathrm{Ca}_{1-x} \mathrm{Mn}_{y} \mathrm{O}_{3-\delta}$ perovskite electrocatalysts. These two ternary perovskites are examples of B-site and A-site substitution along the pseudo-binary composition lines, respectively. X-ray diffraction has been used to characterise the perovskite structures. In both cases, we show there is a large region of compositions away from these lines where 
a perovskite structure is observed. In the case of $\mathrm{La}_{x} \mathrm{Mn}_{y} \mathrm{Ni}_{1-y^{-}}$ $\mathrm{O}_{3-\delta}$ there appears to be a continual distortion of the $\mathrm{LaMnO}_{3}$ cubic structure to a rhombohedral $\mathrm{LaNiO}_{3}$ structure along the tie-line. There is, however, evidence of some A-site substitution of $\mathrm{Mn}^{2+}$ in the $\mathrm{LaMnO}_{3}$, and more extensive A-site substitution of $\mathrm{Ni}^{2+}$ in La sub-stoichiometric compositions of $\mathrm{La}_{x} \mathrm{Mn}_{y} \mathrm{Ni}_{1-y^{-}}$ $\mathrm{O}_{3-\delta}$. In the case of the $\mathrm{La}_{x} \mathrm{Ca}_{1-x} \mathrm{Mn}_{y} \mathrm{O}_{3-\delta}$ perovskites, there appears to be a continual distortion of the $\mathrm{LaMnO}_{3}$ cubic structure $(P m \overline{3} m)$ to an orthorhombic structure (Pnma) in $\mathrm{La}_{x^{-}}$ $\mathrm{Ca}_{1-x} \mathrm{Mn}_{y} \mathrm{O}_{3-\delta}$, and with a change back to a cubic $(P m \overline{3} m)$ structure in $\mathrm{CaMnO}_{3}$.

High throughput electrochemical screening has been undertaken a systematic study of the surface redox behaviour, and the oxygen reduction reaction (ORR) and oxygen evolution reaction (OER) on the synthesised perovskites. In the case of $\mathrm{La}_{x} \mathrm{Mn}_{y} \mathrm{Ni}_{1-y} \mathrm{O}_{3-\delta}$ compositions along the tie-line, there is an anti-correlation in the ORR and OER activities. We identify, however, a region of catalyst compositions with lanthanum Asite sub-stoichiometry where both high ORR and OER activity is observed, and this also correlates with the appearance of the $\mathrm{Mn}^{3+} / \mathrm{Mn}^{4+}$ redox couple. The optimal reversible ORR/OER activity is observed for $\mathrm{La}_{0.85} \mathrm{Mn}_{0.7} \mathrm{Ni}_{0.45} \mathrm{O}_{3-\delta}$. This compositional region of reversible ORR/OER elecrocatalytic activity and $\mathrm{Mn}^{3+} / \mathrm{Mn}^{4+}$ redox activity also corresponds to compositions where A-site substitution of $\mathrm{La}^{3+}$ by $\mathrm{Ni}^{2+}$ was suggested based on the X-ray diffraction results. We suggest that the appearance of the $\mathrm{Mn}^{3+} / \mathrm{Mn}^{4+}$ couple is associated with the creation of $\mathrm{Mn}^{4+}$ in the bulk as $\mathrm{La}^{3+}$ is substituted by $\mathrm{Ni}^{2+}$ at the A-site to create a mixed valent system.

To support this interpretation, we also show that a direct Asite substitution of $\mathrm{La}^{3+}$ by the divalent $\mathrm{Ca}^{2+}$ cation in $\mathrm{La}_{x}$ $\mathrm{Ca}_{1-x} \mathrm{Mn}_{y} \mathrm{O}_{3-\delta}$ perovskites, which is expected to result in the mixed valent $\mathrm{Mn}^{2+}$ and $\mathrm{Mn}^{4+}$ perovskite, also results in the appearance of the $\mathrm{Mn}^{3+} / \mathrm{Mn}^{4+}$ redox couple in cyclic voltammetry centred near to the tie-line, with the maximum charge observed for $\mathrm{La}_{0.3} \mathrm{Ca}_{0.6} \mathrm{Mn}_{1.1} \mathrm{O}_{3-\delta}$. We also show that the compositional distribution of catalysts which exhibit the most reversible ORR/OER electrocatalysts also correlates with the presence of the $\mathrm{Mn}^{3+} / \mathrm{Mn}^{4+}$ redox couple.

In these two La-Mn based perovskite systems investigated, therefore, La A-site substitution by a divalent cation (either $\mathrm{Ni}^{2+}$ or $\mathrm{Ca}^{2+}$ ) which results in the creation of a mixed valent $\mathrm{Mn}^{3+}$ and $\mathrm{Mn}^{4+}$ bulk lattice also results in the appearance of the $\mathrm{Mn}^{3+} / \mathrm{Mn}^{4+}$ redox couple. The appearance of the $\mathrm{Mn}^{3+} / \mathrm{Mn}^{4+}$ redox couple is also shown to be responsible for the creation of the most active reversible ORR/OER electrocatalysts. These observations are consistent with $a b$ initio calculations on $\mathrm{Mn}$ oxides which predict the active site for ORR being $\mathrm{HO}^{*}$ on $\mathrm{Mn}^{3+}$ and for OER is $\mathrm{O}^{*}$ on $\mathrm{Mn}^{4+} \cdot{ }^{8}$ It is this single bifunctional site mediating the $\mathrm{Mn}^{3+} / \mathrm{Mn}^{4+}$ redox couple in the perovskites resulting in the most reversible electrocatalysis. Mixed valent $\mathrm{Mn}^{3+}$ and $\mathrm{Mn}^{4+}$ in the bulk lattice of the perovskite appears to be sufficient to generate this active site. It is the proximity of the potential of the $\mathrm{Mn}^{3+} / \mathrm{Mn}^{4+}$ redox couple to the reversible ORR/ OER potential in the alkali environment which results in the reversible activity. We suggest that a similar strategy of A-site substitution could be more widely used in producing mixed cation occupation at the B-site of perovskites generally, and the resulting couple tuned to support single (bifunctional) site reversible ORR/OER activity.

\section{Conflicts of interest}

There are no conflicts to declare.

\section{Acknowledgements}

We acknowledge the support of the Toyota Research Institute for funding this work.

\section{References}

1 R. Gao, L. Liu, Z. B. Hu, P. Zhang, X. Z. Cao, B. Y. Wang and X. F. Liu, J. Mater. Chem. A, 2015, 3, 17598-17605.

2 D. Chen, C. Chen, Z. M. Baiyee, Z. Shao and F. Ciucci, Chem. Rev., 2015, 115, 9869-9921.

3 J. Suntivich, H. A. Gasteiger, N. Yabuuchi, H. Nakanishi, J. B. Goodenough and Y. Shao-Horn, Nat. Chem., 2011, 3, 546-550.

4 J. Suntivich, K. J. May, H. A. Gasteiger, J. B. Goodenough and Y. Shao-Horn, Science, 2011, 334, 1383-1385.

5 E. Fabbri, R. Mohamed, P. Levecque, O. Conrad, R. Kotz and T. J. Schmidt, ChemElectroChem, 2014, 1, 338-342.

6 Y. L. Zhu, W. Zhou, J. Yu, Y. B. Chen, M. L. Liu and Z. P. Shao, Chem. Mater., 2016, 28, 1691-1697.

7 N. Ramaswamy, R. J. Allen and S. Mukerjee, J. Phys. Chem. C, 2011, 115, 12650-12664.

8 H. Y. Su, Y. Gorlin, I. C. Man, F. Calle-Vallejo, J. K. Norskov, T. F. Jaramillo and J. Rossmeisl, Phys. Chem. Chem. Phys., 2012, 14, 14010-14022.

9 A. S. Ryabova, F. S. Napolskiy, T. Poux, S. Y. Istomin, A. Bonnefont, D. M. Antipin, A. Y. Baranchikov, E. E. Levin, A. M. Abakumov, G. Kéranguéven, E. V. Antipov, G. A. Tsirlina and E. R. Savinova, Electrochim. Acta, 2016, 187, 161-172.

10 K. A. Stoerzinger, W. Lu, C. Li, Ariando, T. Venkatesan and Y. Shao-Horn, J. Phys. Chem. Lett., 2015, 6, 1435-1440.

11 M. Yuasa, N. Yamazoe and K. Shimanoe, J. Electrochem. Soc., 2011, 158, A411-A416.

12 J. Tulloch and S. W. Donne, J. Power Sources, 2009, 188, 359366.

13 K. A. Stoerzinger, M. Risch, J. Suntivich, W. M. Lü, J. Zhou, M. D. Biegalski, H. M. Christen, Ariando, T. Venkatesan and Y. Shao-Horn, Energy Environ. Sci., 2013, 6, 1582-1588.

14 J. Hu, L. Wang, L. Shi and H. Huang, J. Power Sources, 2014, 269, 144-151.

15 X. Z. Yuan, X. X. Li, W. Qu, D. G. Ivey and H. J. Wang, ECS Trans., 2011, 35, 11-20.

16 V. Celorrio, L. Calvillo, E. Dann, G. Granozzi, A. Aguadero, D. Kramer, A. E. Russell and D. J. Fermín, Catal. Sci. Technol., 2016, 6, 7231-7238.

17 B. E. Hayden and F. K. Rogers, J. Electroanal. Chem., 2018, 819, 275-282. 
18 M. C. Sánchez, J. García, J. Blasco, G. Subías and J. PerezCacho, Phys. Rev. B: Condens. Matter Mater. Phys., 2002, 65, 144409.

19 M. N. Iliev, H. Guo and A. Gupta, Appl. Phys. Lett., 2007, 90, 151914.

20 J. S. Kang, G. Kim, H. J. Lee, S. Kolesnik, B. Dabrowski, H. Lee, J. Y. Kim, J. Lee, B. Kim and B. I. Min, J. Appl. Phys., 2009, 105, 07d721.

21 A. N. Demina, V. A. Cherepanov, A. N. Petrov and M. V. Klokova, Inorg. Mater., 2005, 41, 736-742.

22 J. Sunarso, A. A. J. Torriero, W. Zhou, P. C. Howlett and M. Forsyth, J. Phys. Chem. C, 2012, 116, 5827-5834.

23 X. Liu, X. Liu, J. Meng, C. Yao, X. Zhang, J. Wang and J. Meng, Int. J. Hydrogen Energy, 2016, 41, 22361-22372.

24 S. Guerin and B. E. Hayden, J. Comb. Chem., 2006, 8, 66-73. 25 B. E. Hayden and S. Yakovlev, Thin Solid Films, 2016, 603, 108-114.

26 A. David, S. Guérin, B. E. Hayden, R. Noble, J.-P. Soulié, C. Vian, I. P. Koutsaroff, S. i. Higai, N. Tanaka, T. Konoike, A. Ando, H. Takagi, T. Yamamoto, T. Fukura and H. Ieki, Cryst. Growth Des., 2014, 14, 523-532.

27 M. S. B. Darby, S. Guerin, B. E. Hayden, H.-J. Schreiner and S. Yakovlev, J. Appl. Phys., 2013, 113, 014104.

28 C. Yada, C. E. Lee, D. Laughman, L. Hannah, H. Iba and B. E. Hayden, J. Electrochem. Soc., 2015, 162, A722-A726.

29 M. S. Beal, B. E. Hayden, T. Le Gall, C. E. Lee, X. J. Lu, M. Mirsaneh, C. Mormiche, D. Pasero, D. C. A. Smith, A. Weld, C. Yada and S. Yokoishi, ACS Comb. Sci., 2011, 13, 375-381.

30 S. Guerin, B. E. Hayden, C. E. Lee, C. Mormiche and A. E. Russell, J. Phys. Chem. B, 2006, 110, 14355-14362.

31 S. Guerin, B. E. Hayden, C. E. Lee, C. Mormiche, J. R. Owen, A. E. Russell, B. Theobald and D. Thompsett, J. Comb. Chem., 2004, 6, 149-158.

32 B. E. Hayden, S. Guerin, D. Pletcher, M. E. Rendall and J. P. Suchsland, J. Comb. Chem., 2006, 8, 679-686.

33 M. J. Sayagués, J. M. Córdoba and F. J. Gotor, J. Solid State Chem., 2012, 188, 11-16.
34 R. D. Shannon, Acta Crystallogr., Sect. A: Cryst. Phys., Diffr., Theor. Gen. Crystallogr., 1976, 32, 751-767.

35 R. Horyń, A. Sikora and E. Bukowska, J. Alloys Compd., 2003, 353, 153-169.

36 M. Wołcyrz, R. Horyń, F. Bourée and E. Bukowska, J. Alloys Compd., 2003, 353, 170-174.

37 W. Pon-On, S. Meejoo, A. Mehtar and I. M. Tang, Ceram. Int., 2011, 37, 2075-2079.

38 A. Tkach, P. M. Vilarinho and A. L. Kholkin, Acta Mater., 2005, 53, 5061-5069.

39 R. N. Singh, L. Bahadur, J. P. Pandey, S. P. Singh, P. Chartier and G. Poillerat, J. Appl. Electrochem., 1994, 24, 149-156.

40 D. S. Hall, C. Bock and B. R. MacDougall, J. Electrochem. Soc., 2013, 160, F235-F243.

41 S. Krishnan, V. Sharma, P. Singh and R. Ramprasad, J. Phys. Chem. C, 2016, 120, 22126-22133.

42 C. Singh and M. Rakesh, Indian J. Eng. Mater. Sci., 2009, 16, 288-290.

43 C. Zener, Phys. Rev., 1951, 82, 3.

44 C. Doroftei, P. D. Popa and F. Lacomi, Sens. Actuators, A, 2012, 173, 24-29.

45 Y. B. Zuo, J. H. Li, J. X. Yi, Z. B. Wang and C. S. Chen, J. Solid State Chem., 2008, 181, 700-704.

46 K. Suresh, T. S. Panchapagesan and K. C. Patil, Solid State Ionics, 1999, 126, 299-305.

47 S. Ponce, M. A. Pena and J. L. G. Fierro, Appl. Catal., B, 2000, 24, 193-205.

48 W. Zhong, C. T. Au and Y. W. Du, Chin. Phys. B, 2013, 22, 11. 49 R. von Helmolt, J. Wecker, B. Holzapfel, L. Schultz and K. Samwer, Phys. Rev. Lett., 1993, 71, 2331-2333.

50 S. Jin, T. H. Tiefel, M. McCormack, R. A. Fastnacht, R. Ramesh and L. H. Chen, Science, 1994, 264, 413-415.

51 Z. Arnold, K. Kamenev, M. R. Ibarra, P. A. Algarabel, C. Marquina, J. Blasco and J. García, Appl. Phys. Lett., 1995, 67, 2875-2877.

52 Z. Wei, A. Chak-Tong and D. You-Wei, Chin. Phys. B, 2013, 22, 11.

53 V. Celorrio, E. Dann, L. Calvillo, D. J. Morgan, S. R. Hall and D. J. Fermin, ChemElectroChem, 2016, 3, 283-291. 